\title{
Seasonal changes in soil TN and SOC in a seawall-reclaimed marsh in the Yellow River Delta, China
}

\author{
Dehua Qin • Meng Gao • Xiaoqing Wu • Xiaoyan Du • \\ Xiaoli Bi
}

Received: 12 November 2014 / Revised: 1 December 2014 / Accepted: 8 December 2014 / Published online: 10 January 2015

(C) Springer Science+Business Media Dordrecht 2015

\begin{abstract}
Coastal salt marsh has been globally fragmented by man-made coastal seawalls. However, the dynamic changes in community structure and abiotic environments in these regenerated marsh after seawall reclamation are largely unknown. We analyzed the seasonal changes of soil nutrient pools and the direction effects on them. The results showed that soil total nitrogen (TN) has decreased but soil organic carbon (SOC) has increased from May to September. Direction has influenced the patterns and seasonal changes in soil TN and SOC. The potential influencing factors have been largely contributed to soil salinity reduction, vegetation growth, microorganism activities with different seasonal characteristics. Researches on seasonal dynamic of marsh regeneration after seawall reclamation can provide us helpful information to understand mechanism of marsh restoration and design coastal marsh restoration projects.
\end{abstract}

Keywords Soil total nitrogen (TN) · Soil organic carbon (SOC) · Coastal marsh · Seawall · The Yellow River Delta

\section{Introduction}

Recent decades, coastal landscapes were altered globally by the introduction of man-made infrastructures, such as seawalls, dykes, breakwaters which were used to protect coastal

D. Qin

College of Agronomy, Henan University of Science and Technology, Luoyang 471003, China

$\mathrm{M} . \mathrm{Gao} \cdot \mathrm{X} . \mathrm{Wu} \cdot \mathrm{X} . \mathrm{Du} \cdot \mathrm{X} . \mathrm{Bi}(\bowtie)$

Yantai Institute of Coastal Zone Research, Chinese Academy of Sciences, Yantai 264003, China

e-mail: xlbi@yic.ac.cn cities from tidal storm, seawater invasion as well as sea level rising (Airoldi and Bulleri 2011; Temmerman et al. 2013; Ma et al. 2014). According to a report from IPCC in 2013, the global sea level rising will be $0.44-0.74 \mathrm{~m}$ in the next century (http://www.ipcc.ch/report/ar5/wg1/), which may need more seawalls to enhance the safety of coastal zones.

Coastal salt marshes are important habitats for many plant and animal species because their valuable ecosystem services (Kennish 2001). The increasing development of coastal infrastructures will prevent natural salt marsh from migrating landward into the upland and in many areas this will easily result in marsh fragmentation or loss and series of changes in structure and functions of those natural ecosystems (Temmerman et al. 2013). However, it will take many years for restored salt marshes to develop communities similar to those in natural habitats (Garbutt and Wolters 2008). Salt marshes that regenerated on abandoned land reclaimed by seawalls have been used, to certain extent, as natural analogues for salt marsh development. Particular attentions have been given to the succession of plant communities (Bakker et al. 2002; Bozek and Burdick 2005; Wolters et al. 2005; Garbutt and Wolters 2008) and restoration of soil nutrient pools, soil seed bank (Santin et al. 2009; Fernandez et al. 2010; Hung et al. 2013; Zhang et al. 2013; Bai et al. 2014; Gilland and McCarthy 2014; Wang et al. 2014). Those researches could provide general information on the design and management of coastal marsh restoration schemes (Garbutt and Wolters 2008).

To date, timescales of those researches have usually based on spatial comparisons between restored salt marshes with different ages (Morgan and Short 2002). However, dynamic changes in community structure and abiotic environments in these regenerated marsh ecosystems are largely unknown. Researches on the spatio-temporal patterns of marsh regeneration after seawall reclamation can help us to understand the restoration mechanism of salt marsh and thus provide conservation policy for coastal marsh after seawall reclamation. 
Therefore, in this study we analyze the seasonal changes in soil nutrient pools in a regenerated coastal marsh after about 30 years of seawall reclamation. Our objects were to examine: (1) the seasonal characteristics in soil total nitrogen (TN) and soil organic carbon (SOC), (2) the spatial patterns of those changes along the sea-land gradient, and (3) the factors which potentially influence the spatio-temporal patterns in the regenerated marsh. In particular, we considered the influences of direction, an important factor determining salt and water stress along the sea-land gradient, but usually being ignored in previous researches.

\section{Methods}

Study area

The Yellow River Delta is located in the northern part of Shandong Province, China, and on the southwest coast of the Bohai Sea (Bi et al. 2011) (Fig. 1). The climate condition, soil types and natural vegetation distribution were described by He et al. (2011).

\section{Filed investigation}

Filed investigation was conducted at Zhuangxi, the most northern merge of this delta (Fig. 1). Since 1980's, the tidal flat was reclaimed by seawalls and roads to protect the Zhuangxi Oil field and its inland DongYing City from storm tides. On early May and middle September in 2013, two transects, with the length of $500 \mathrm{~m}$, were selected to be vertical to the seawalls, along the sea-land gradient in different directions (A: North-south, NS; B: East-west, EW, respectively). Samples were designated at $5 \mathrm{~m}$ intervals using a global positioning system device (GPSMAP62sc, made in China). There are 100 samples for each transect (Fig. 1).

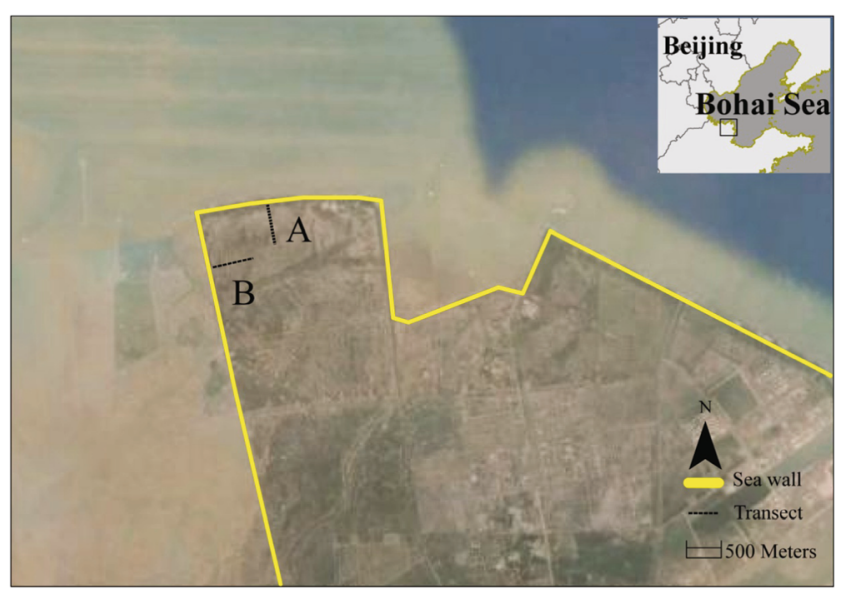

Fig. 1 Location of study area
For each sample, two soil cores $(15 \mathrm{~cm}$ deep and $2 \mathrm{~cm}$ diameter) were collected: one for soil salinity, soil $\mathrm{TN}$ and SOC as well as soil C:N rate and one for root biomass. All of above ground biomass, including grass green biomass and litter mass, from a $0.5 \times 0.5 \mathrm{~m}$ plot centered on each soil sample were collected and then oven-dried for at least $72 \mathrm{~h}$ at $60{ }^{\circ} \mathrm{C}$ for dry weight.

Lab analysis

Soil samples were air-dried and crushed. Roots and gravel were removed and then the soils were passed through a 2-mm sieve. Electrical conductivity $\left(\mathrm{EC}_{e}\right)$, as the standard measure of soil salinity, was measured by a conductivity meters (TP320, made in China). Soil TN and SOC were measured by an elemental analyzer (Vario MACRO cube, made in Germany). Root biomass was obtained by washing the soil cores and the collected roots were dried for at least $72 \mathrm{~h}$ at $60{ }^{\circ} \mathrm{C}$ to determine dry weight.

\section{Statistical methods}

One-way ANOVA was used to compare the seasonal differences in soil and plant variables for A and B, respectively, and the orientation differences between $\mathrm{A}$ and $\mathrm{B}$.

Linear regression was use to analyze the spatial effects of seawall on soil TN and SOC. Pearson correlation analysis was used to examine the factors which may potentially influence soil TN and SOC in A and B. All of those analyses were conducted by SPSS Windows 13.0.

\section{Results}

Seasonal changes in soil TN and SOC and other related variables

In the seawall reclaimed wetland, soil SOC, C:N rate, salinity, and root biomass have exhibited significantly differences in different directions (Table 1) and these variables have significantly seasonal changes. For instance, soil TN and salinity have decreased while soil SOC, C:N rate and biomass variables have increased from May to September (Fig. 2).

In the N_S transect, only root biomass showed insignificantly changes in May and September (Table 1). Soil TN and soil salinity have significantly decreased while soil SOC, C:N rate and above ground biomass have significantly increased (Fig. 2).

In the E_W transect, above ground biomass, root biomass and soil SOC have no significant changes from May to September (Table 1). Soil $\mathrm{TN}$ and soil salinity have 
Table 1 Significant level (Pvalues) of ANOVA results for seasonal changes in $\mathrm{A}$ and $\mathrm{B}$, respectively and ordination differences in $\mathrm{A}$ and $\mathrm{B}$

\begin{tabular}{lcccccc}
\hline & Soil TN & Soil SOC & Soil C:N rate & Soil salinity & Above ground biomass & Root biomass \\
\hline A & 0.006 & 0.021 & $<0.0001$ & $<0.0001$ & 0.0025 & 0.589 \\
B & 0.023 & 0.333 & $<0.0001$ & $<0.0001$ & 0.157 & 0.665 \\
A_B & 0.612 & 0.000 & 0.000 & 0.002 & 0.118 & 0.000 \\
\hline
\end{tabular}

significantly decreased whereas soil C:N rate has significantly increased (Fig. 2).

Changes in the spatial pattern along the sea-land gradient

In order to identify the spatial pattern of seasonal changes in soil variables, we analysis the linear regressions between the changing rate of soil TN, SOC and C:N rate and distance to seawall. The results showed that from May to September, soil TN has clearly decreased with the distance to seawall in both $\mathrm{A}$ and B (both P-values $<0.0001$ ). However, the rate of soil SOC has no obvious changes along the sea-land gradient in A
( $P=0.86)$, but it has decreased with distance to seawall in $\mathrm{B}(P<0.0001)$.

The changing rates of $\mathrm{C}: \mathrm{N}$ rate in both $\mathrm{A}$ and $\mathrm{B}$ have similarly increased with distance to seawall (both P-values $<0.001$ ) (Fig. 3).

Pearson correlations between soil TN and SOC with other variables

Pearson correlation analysis showed that in the N S direction, the influences of potential factors on soil TN and SOC have changed few from May to September, whereas in the E_W
Fig. 2 Different values of mean and S.D. on May and September in A and B. Black bar: N-S direction; Gray bar: E-W direction
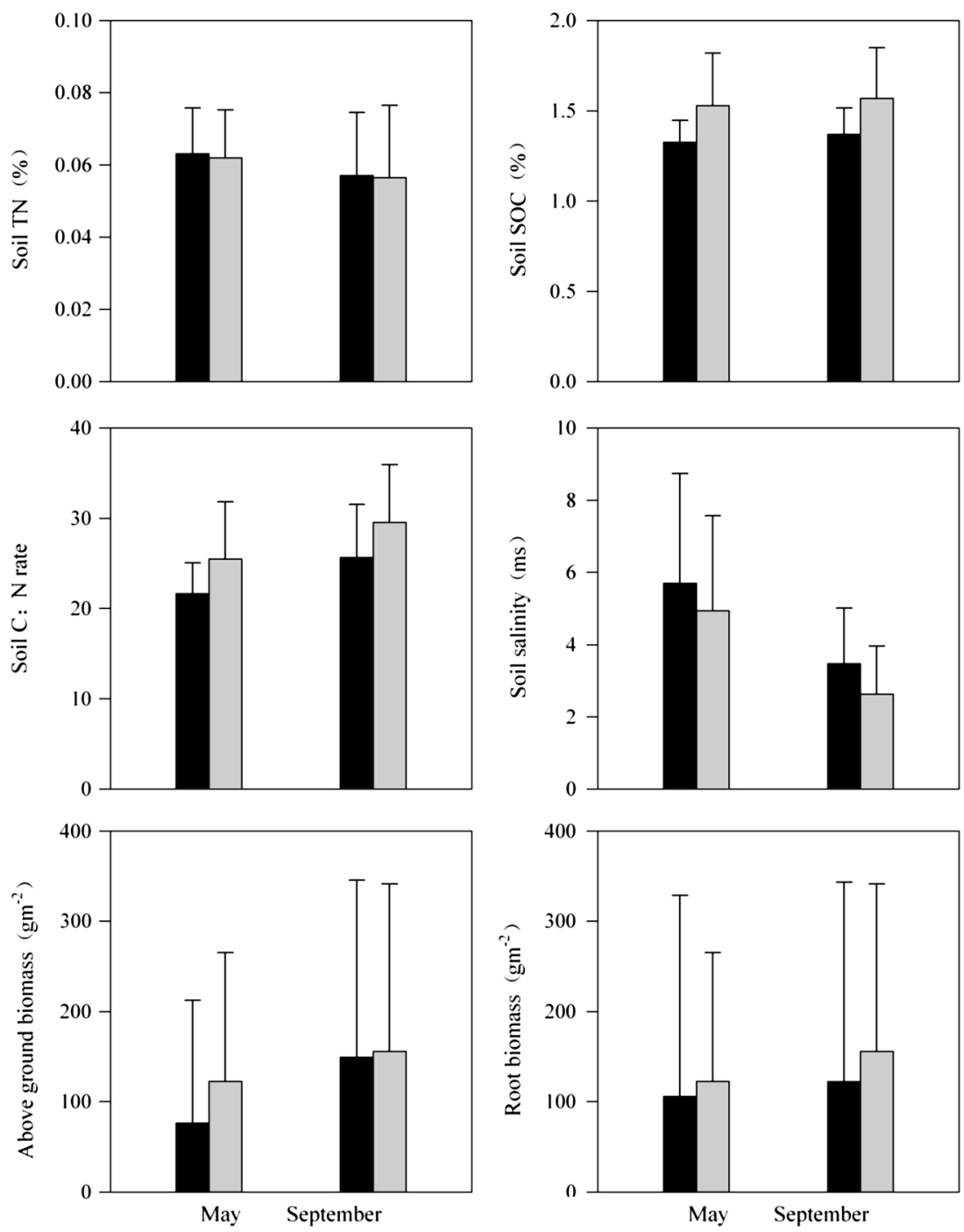
Fig. 3 The rates of changes along the sea-land gradient. Dark dot: N-S direction; Dark triple: E-S direction
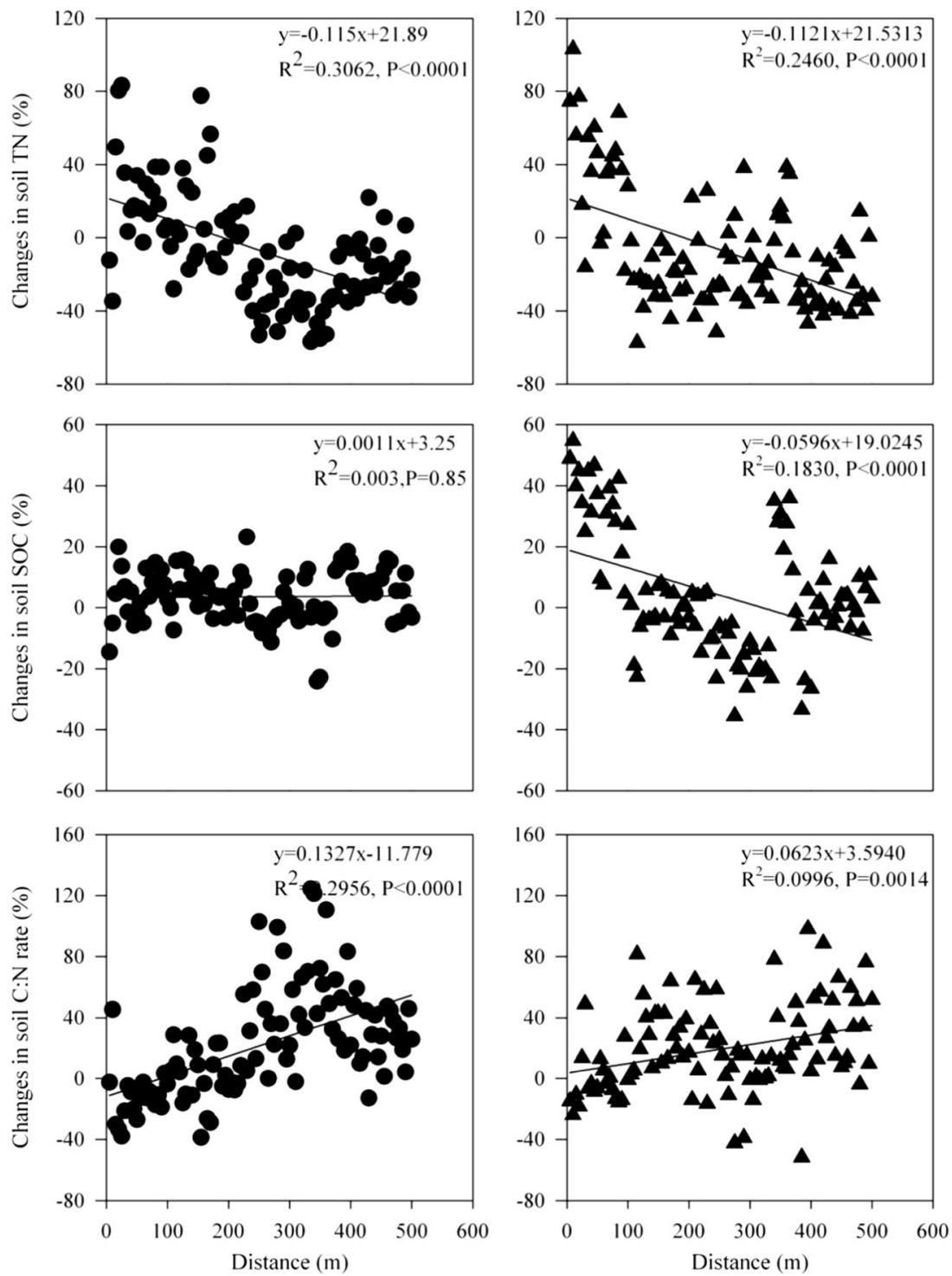

direction, those influences on soil TN have changed few but those influences on SOC have changed greatly.

For instance, soil TN has closely and positively related to above ground biomass, while closely and negatively related to soil C:N rate and soil salinity, in May and September, in both $\mathrm{A}$ and $\mathrm{B}$ (Tables 2 and 3).
Soil SOC has closely and positively related to above ground biomass and root biomass and closely and negatively related to soil $\mathrm{C}: \mathrm{N}$ rate and salinity in May and September in $\mathrm{A}$ (Table 2). However, in $\mathrm{B}$, there is no variables significantly related to soil SOC, except soil C:N rate in May. Comparably, soil SOC was significantly and positively related to above
Table 2 Pearson coefficients between soil and plant variables in May and September in A (N-S direction) ns: non-significant

$* P<0.05$ and $* * P<0.01$

\begin{tabular}{lllllc}
\hline & Soil SOC & Soil C:Nrate & Soil salinity & Above ground biomass & Root biomass \\
\hline May & & & & & \\
Soil TN & $0.609^{* *}$ & $-0.870^{* *}$ & $-0.468^{* *}$ & $0.398^{* *}$ & $\mathrm{~ns}$ \\
Soil SOC & 1 & $-0.219^{*}$ & $-0.622^{* *}$ & $0.549^{* *}$ & $0.275^{* *}$ \\
September & & & & & $\mathrm{ns}$ \\
Soil TN & $0.691^{* *}$ & $-0.900^{* *}$ & $-0.274^{* *}$ & $0.336^{* *}$ & $0.348^{* *}$ \\
Soil SOC & 1 & $-0.428^{* *}$ & $-0.589^{* *}$ & $0.450^{* *}$ &
\end{tabular}


Table 3 Pearson coefficients between soil and plant variables in May and September in B (E-W direction)

$* P<0.05$ and $* * P<0.01$

Soil SOC

Soil C:Nrate

Soil salinity

Above ground biomass

Root biomass

May

Soil TN

$0.185^{*}$

$-0.614^{* *}$

Soil SOC

September

Soil TN

Soil SOC
1

$0.784 * * \quad-0.800 * *$

1

$-0.303 * *$

$0.358 * *$
$\mathrm{~ns}$
$0.419^{* *}$
$0.389 * *$

$0.389 * *$
$-0.406^{* *}$
$\mathrm{~ns}$
$-0.431^{* *}$
$-0.455^{* *}$ ns

ns

ns

ns ground biomass and negatively related to soil $\mathrm{C}: \mathrm{N}$ rate and salinity in September(Table 3).

\section{Discussion}

The storages of soil nutrient pools are counterbalances of inputs and outputs during a certain period, which has been widely recognized to be sensitive to environmental changes and human disturbances (Macreadie et al. 2013; Wang et al. 2014). Our results have proved that soil TN and SOC have clear seasonal characteristics and significantly directional differences after seawall disturbances. In the regenerated marsh, soil nutrient pools have responded potentially to the salinity reduction, plant growth, as well as potential microorganism activities due to seawall reclamation and season change.

Our research has demonstrated that the direction has influenced soil SOC rather than soil TN at a large scale. Through influencing the direction of wind, flooding and even process of vegetation succession in the man-made land, direction may play important roles in determining patterns of soil carbon pools in this regenerated marsh. However, in spite of its roles in the process of marsh restoration, direction is seldom considered in recent studies. Therefore, future works should carefully consider its influences, e.g. on soil SOC or carbon cycling, in order to scientifically assess the effects of seawall on coastal wetlands.

In the growth season, soil TN has decreased whereas soil SOC has increased in the regenerated marsh. Soil salinity, the significant environmental factor, has decreased in summer because of the leaching of prepetition (Table 1, Fig. 2). Correspondingly, the plant productivity, both above ground and root biomass have increased in the summer growth, which lead to a higher biomass accumulation in soil, resulting in the increase of soil SOC (Fig. 2). In contrast, the mean soil TN in this marsh has decreased from May to September, which indicated a potential consummation deficit. It is demonstrated that in the Yellow river Delta, $\mathrm{N}$ is the main limiting factor in salt marsh growth. During the summer, marsh plants have absorbed more nitrogen in soil for growth, which lead to the reduction of soil TN (Li et al. 2012). Changes in soil TN and soil SOC indicated a trade-off between consummation and accumulation of soil nutrients, which may similar with the natural salt marsh.

Soil TN rather than soil SOC has changed over the distance to seawall, which indicated that environmental heterogeneity has played extremely important roles in determining the spatial pattern of soil TN in this regenerated marsh. Therefore, those factors which have obvious spatial patterns were closely related to soil TN, such as, soil C:N rate, soil salinity, above ground biomass. Comparatively, soil SOC, especially along the sea-land gradient, has been in a relatively stable condition. Besides soil C:N rate, soil salinity, above ground biomass, it was also closely related to root biomass. In addition, the interactions between soil TN and influencing factors have changed little over time and direction. However, the interactions between soil SOC and its influencing factors were different over time and direction, which suggested a complex mechanism in maintaining the balance in soil SOC.

Coastal salt marsh restoration is rapidly approaching a scale of planning, design, and implementation that require additional scientific understanding of entirely different spatial and temporal perspective (Simenstad et al. 2006). Recovering natural system dynamics must include the disturbances which cannot be controlled in initiating restoration, but must be considered when designing restoration projects. The changing pattern in soil nutrients of the reclaimed marsh is a result of the combined effects of drivers over time, such as wind, flooding, drought and rainfall (Fernandez et al. 2010; Hung et al. 2013). The effects of seawall reclamation on salt marsh and its soil environments might be reflected at various spatial and temporal scales. In our case, the effects of direction of seawall showed a significant consequences. Unfortunately, most wetland planning projects have not even mentioned this point (Cai et al. 2014). At the same time, the result about direction effects of seawall can also provide new insight to seawall management and planning.

In addition, recognition of dynamic changes in a seawall reclaimed marsh can help us to understand the mechanism of marsh self-restoration. The seasonal changes in soil nutrient pools can response to the changes in primary production, plant species diversity and even microorganism activates (Hao et al. 2013). Recognizing the seasonal changes in plant-soil interactions can help us assess the health condition of restored salt marsh ecosystem. 


\section{Conclusion}

In this paper, seasonal characteristics in soil total nitrogen (TN) and soil organic carbon (SOC) in a seawall reclaimed marsh in the Yellow River Delta, China were investigated. The influence of direction on soil nutrient pools in this marsh was also studied. The results have demonstrated that direction has influenced the distribution of soil nutrient pools and their influencing factors. In the growth season, soil TN has decreased but soil SOC has increased. Change rate of soil TN has decreased with distance to seawall, whereas the rate of soil SOC has no clear pattern along the sea-land gradient. In addition, the influencing factors on soil SOC may behavior more complex than on soil TN. Our works on dynamic changes in soil nutrient pools in a seawall impacted area can provide useful information for understanding the restoration mechanism of disturbed marsh and designing the future coastal marsh protection projects.

Acknowledgments This research was funded by the National Natural Science Foundation of China (No. 41301596, 31000197), Yantai Institute of Coastal Zone Research, Chinese Academy of Sciences (No.Y254021031), the Knowledge Innovation Project of Chinese Academy of Sciences (KZCX2-EW-QN209) and the National High Technology Research and Development Program of China (2013AA06A211-4). We thank Prof. Hua Zhang, Dr. Gaosheng Zhang and Dr. Yang Tan for assistance with lab analyses. We also thank the anonymous individuals for reviewing this manuscript.

\section{References}

Airoldi L, Bulleri F (2011) Anthropogenic disturbance can determine the magnitude of opportunistic species responses on marine urban infrastructures. PLoS One 6:e22985

Bai J, Huang L, Gao Z, Lu Q, Wang J, Zhao Q (2014) Soil seed banks and their germination responses to cadmium and salinity stresses in coastal wetlands affected by reclamation and urbanization based on indoor and outdoor experiments. J Hazrd Mater 280:295-303

Bakker JP, Esselink P, Dijkema KS, van Duin WE, de Jong DJ (2002) Restoration of salt marshes in the Netherlands. Hydrobiologia 478:29-51

Bi X, Wang B, Lu Q (2011) Fragmentation effects of oil wells and roads on the Yellow River Delta, North China. Ocean Coast Manag 54: 256-264

Bozek CM, Burdick DM (2005) Impacts of seawalls on saltmarsh plant communities in the Great Bay Estuary, New Hampshire USA. Wetl Ecol Manag 13:553-568
Cai WQ, Meng W, Liu LS, Lin KX (2014) Evaluation of the ecological status with benthic indices in the coastal system: the case of Bohai Bay (China). Front Environ Sci Eng 8:737-746

Fernandez S, Santin C, Marquinez J, Alvarez MA (2010) Saltmarsh soil evolution after land reclamation in Atlantic estuaries (Bay of Biscay, North coast of Spain). Geomorphology 114:497-507

Garbutt A, Wolters M (2008) The natural regeneration of salt marsh on formerly reclaimed land. Appl Veg Sci 11:335-344

Gilland KE, McCarthy BC (2014) Microtopography influences early successional plant communities on experimental coal surface mine land reclamation. Restor Ecol 22:232-239

Hao C, Smith J, Zhang JH, Meng WQ, Li HY (2013) Simulation of soil carbon changes due to land use change in urban areas in China. Front Environ Sci Eng 7: 255-266

He Q, Cui B, An Y (2011) The importance of facilitation in the zonation of shrubs along a coastal salinity gradient. J Veg Sci 22:828-836

Hung JJ, Huang WC, Yu CS (2013) Environmental and biogeochemical changes following a decade's reclamation in the Dapeng (Tapong) Bay, southwestern Taiwan. Estuar Coast Shelf Sci 130:9-20

Kennish MJ (2001) Coastal salt marsh systems in the US: a review of anthropogenic impacts. J Coast Res 17:731-748

Li Z, Han L, Liu Y, An S, Leng X (2012) C, N, and P stoichiometric characteristics in leaves of Suaeda salsa during different growth phase in coastal wetlands of China. Chin J Plant Ecol 36:1054-1061

Ma ZJ, Melville D, Liu JG, Chen Y, Yang HY, Ren WW, Zhang ZW, Piersma T, Li B (2014) Rethinking China's new great wall. Science 346:912-914

Macreadie PI, Hughes AR, Kimbro DL (2013) Loss of 'Blue Carbon' from coastal salt marshes following habitat disturbance. Plos One 8: e69244

Morgan PA, Short FT (2002) Using functional trajectories to track constructed salt marsh development in the Great Bay Estuary, Maine/ New Hampshire, USA. Restor Ecol 10:461-473

Santin C, de la Rosa JM, Knicker H, Otero XL, Alvarez MA, GonzalezVila FJ (2009) Effects of reclamation and regeneration processes on organic matter from estuarine soils and sediments. Org Geochem 40: 931-941

Simenstad C, Reed D, Ford M (2006) When is restoration not? Incorporating landscape-scale processes to restore self-sustaining ecosystems in coastal wetland restoration. Ecol Eng 26:27-39

Temmerman S, Meire P, Bouma TJ, Herman PMJ, Ysebaert T, De Vriend HJ (2013) Ecosystem-based coastal defence in the face of global change. Nature 504:79-83

Wang Y, Wang ZL, Feng X, Guo C, Chen Q (2014) Long-term effect of agricultural reclamation on soil chemical properties of a coastal saline marsh in Bohai Rim, Northern China. PLoS One 9:e93727

Wolters M, Garbutt A, Bakker JP (2005) Salt-marsh restoration: evaluating the success of de-embankments in north-west Europe. Biol Conserv 123:249-268

Zhang ZS, Song XL, Lu XG, Xue ZS (2013) Ecological stoichiometry of carbon, nitrogen, and phosphorus in estuarine wetland soils: influences of vegetation coverage, plant communities, geomorphology, and seawalls. J Soil Sediment 13:1043-1051 